\title{
Measuring the Biodegradability of Plastic Polymers in Olive-Mill Waste Compost with an Experimental Apparatus
}

\author{
Francesco Castellani, ${ }^{1,2}$ Alessandro Esposito, ${ }^{1}$ Vitale Stanzione, ${ }^{1}$ and Roberto Altieri ${ }^{1}$ \\ ${ }^{1}$ Consiglio Nazionale delle Ricerche, Istituto per i Sistemi Agricoli e Forestali del Mediterraneo, Via Madonna Alta 128, \\ 06128 Perugia, Italy \\ ${ }^{2}$ Chair of Production and Logistics, Georg-August-Universität Göttingen, Platz der Göttinger Sieben 3, 37073 Göttingen, Germany \\ Correspondence should be addressed to Roberto Altieri; roberto.altieri@cnr.it
}

Received 18 August 2016; Accepted 18 October 2016

Academic Editor: Peter Chang

Copyright (C) 2016 Francesco Castellani et al. This is an open access article distributed under the Creative Commons Attribution License, which permits unrestricted use, distribution, and reproduction in any medium, provided the original work is properly cited.

\begin{abstract}
The use of biodegradable polymers is spreading in agriculture to replace those materials derived from petroleum, thus reducing the environmental concerns. However, to issue a significant assessment, biodegradation rate must be measured in case-specific standardized conditions. In accordance with ISO 14855-1, we designed and used an experimental apparatus to evaluate the biodegradation rate of three biopolymers based on renewable resources, two poly( $\varepsilon$-caprolactone) (PCL) composites, and a compatibilized polylactic acid and polybutyrate (PLA/PBAT) blend. Biodegradation tests were carried out under composting condition using mature olive-mill waste (OMW) compost as inoculum. Carbon dioxide emissions were automatically recorded by infrared gas detectors and also trapped in saturated $\mathrm{Ba}(\mathrm{OH})_{2}$ solution and evaluated via a standard titration method to check the results. Some of the samples reached more than $80 \%$ biodegradation in less than 20 days. Both the experimental apparatus and the OMW compost showed to be suitable for the cases studied.
\end{abstract}

\section{Introduction}

In the last years, the worldwide production of plastic waste has increased enormously [1]. Following the motto "ReduceReuse-Recycle," European directives have therefore established plastic waste recovery as the first choice in the waste management hierarchy [2]. Consequently, industries are paying increased attention to innovative materials that can be recycled or biodegraded at the end of their life-cycle.

Ever since a first generation of degradable plastics was introduced in the 1980s [3], researchers have been attempting to evaluate the authentic biodegradability of these products [4]. Today, the global competition to produce biodegradable materials is attracting the attention of a variety of scientific branches and commercial sectors (food, packaging, and agroindustries), and it has become even more crucial to identify the true biodegradability of new goods put on the marketsome of which are merely self-proclaimed "biodegradable." Biodegradation results from the action of naturally occurring heterotrophic microorganisms, such as bacteria and fungi.
These use biodegradable compounds as food, converting them into metabolic by-products that have chemical structures remarkably different than the original materials [5].

To evaluate the biodegradability of biopolymers, different standard methods have been defined [6,7]. These are based mainly on measuring carbon dioxide $\left(\mathrm{CO}_{2}\right)$ emissions or oxygen consumption under environmentally controlled conditions [8]. Based on these standard methods, several experimental apparatus have even been proposed. Jayasekara et al. [9], for instance, developed a $\mathrm{CO}_{2}$ monitoring system able to manage up to 36 vessel outlets. Subsequently, Kijchavengkul et al. [10] also tested their own respirometric apparatus. And, more recently, Pantani and Sorrentino [11] carried out biodegradation tests using a homemade respirometric machine equipped with $3 \mathrm{~L}$ glass flasks and an infrared gas analyser. However, very few studies checked their equipment with other methods [12] and analysed different kinds of plastics in the same conditions [13].

Previous literature and our experience in prototyping [14] laid the foundations for our design of an experimental 


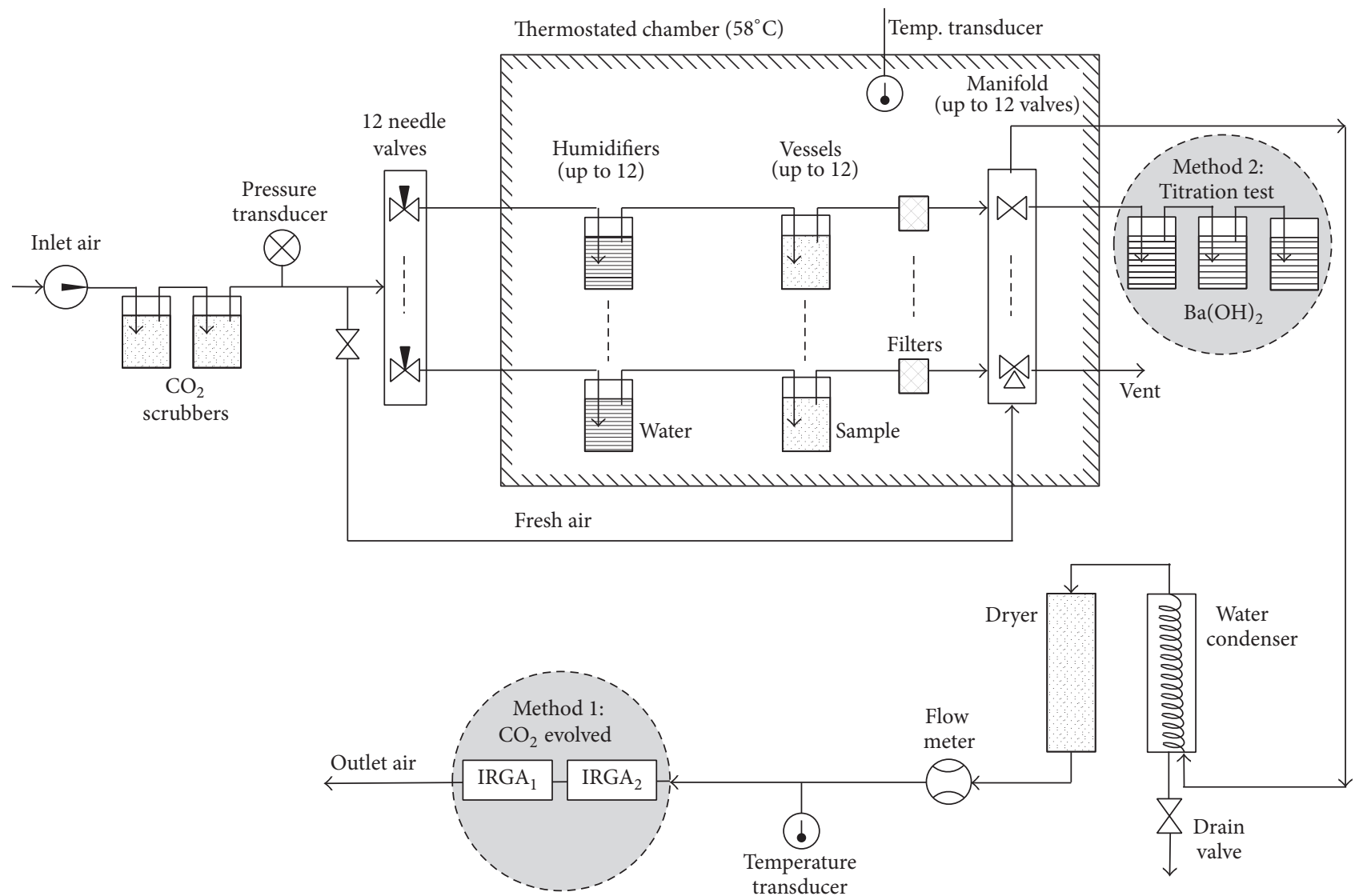

FIGURE 1: Schematic diagram of the experimental apparatus. $\mathrm{CO}_{2}$ evolved (method 1) and titration test (method 2) are used to evaluate the biodegradation of samples.

apparatus for evaluating the biodegradability of biopolymers using OMW compost as inoculum.

In this study, we

(i) describe in detail an experimental apparatus designed and assembled to assess the biodegradation rate of plastic materials under controlled composting conditions, in accordance with the ISO 14855-1:2012 [15];

(ii) test the apparatus by evaluating with infrared gas analysis (IRGA) the cumulative $\mathrm{CO}_{2}$ evolution of three biopolymers made of renewable materials for agricultural applications;

(iii) check the accuracy of the data by measuring the amount of $\mathrm{CO}_{2}$ released during biodegradation with barium hydroxide, $\mathrm{Ba}(\mathrm{OH})_{2}$, titration method.

\section{Materials and Methods}

2.1. Apparatus. The apparatus combines a pneumatic and an electric system. In the pneumatic system, compressed air is used to stimulate aerobic biodegradation of the samples, which are kept in air-tight closed vessels (bioreactors) and exposed to mature compost throughout the trials. The compost (called "inoculum"), rich in living microorganisms, promotes the biodegradation of the samples, thus producing
$\mathrm{CO}_{2} \cdot \mathrm{CO}_{2}$ measurements are performed on the exhausted air by means of the appropriate IRGA sensors. A customized software was developed in LabVIEW (National Instruments, USA) environment for the automatic control of the apparatus. The schematic diagram of the pneumatic system is shown in Figure 1. During trials, the pressurized system ensures optimal aerobic conditions and prevents undesired anaerobic fermentation. We used polymethylmethacrylate, air-tight tubes (4 mm internal diameter) for the pneumatic system and controlled pressure by means of a double-stage regulator (Festo AG \& Co., Germany). Before entering the vessels, air flows into a $\mathrm{CO}_{2}$ scrubber consisting of a series of two $2 \mathrm{~L}$ vessels filled with soda lime (Sofnolime 2550 USP Grade). By reducing the inlet air $\mathrm{CO}_{2}$ concentration to about $10 \mathrm{ppm}$, the $\mathrm{CO}_{2}$ scrubber allows the exhausted air to ultimately match the range of measurement for the $\mathrm{CO}_{2}$ IRGA sensors used (sensors described below). We used a pressure transducer (Dwyer, Germany) to monitor the airflow and highlight possible undesired pressure drops, which are promptly displayed on video by the software. $\mathrm{CO}_{2}$-free air is distributed to the vessels via needle valves, which control the flow.

Twelve $2 \mathrm{~L}$ glass vessels are placed inside an environmental chamber (Gallenkamp, UK) outfitted with a temperature controller and equipped with a suitable passage for the airtight tubes (Figure 2). The chamber temperature is also 


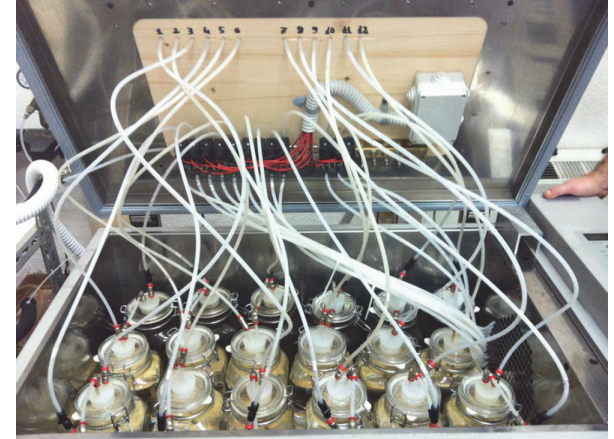

FIGURE 2: Environmental chamber of the experimental apparatus set at $58 \pm 2^{\circ} \mathrm{C}$.

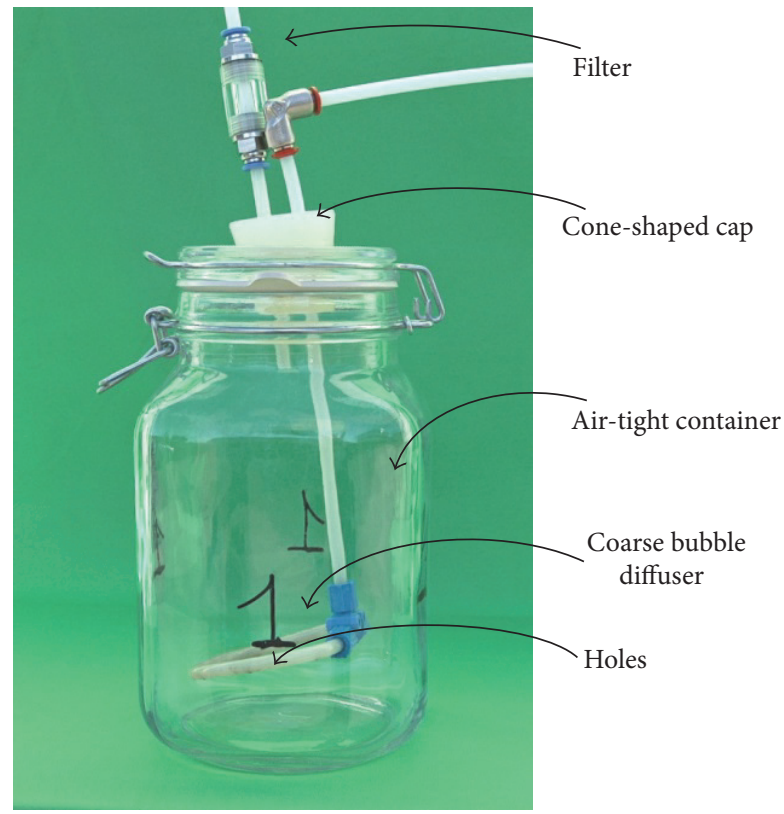

FIGURE 3: Prototyped arrangement for the vessels.

recorded by means of a thermocouple type $\mathrm{T}$ (Tersid, Italy), which is properly connected to the PC. Each vessel is connected in-line with another $2 \mathrm{~L}$ vessel containing distilled water used to humidify the inlet air. Both humidifiers and vessels are equipped with handmade coarse bubble diffusers. These are arranged in a circular scheme and contain multiple fine holes to permit uniform diffusion of the airflow (Figure 3).

An outlet manifold, equipped with low-power microsolenoid-valves and placed inside the chamber to avoid water condensation from the flowing air, drives the air exhausted from each vessel towards the measuring line, where the IRGA sensors are located. Airflow blockage was prevented using plastic filters of $90 \mu \mathrm{m}$ mesh (Preferred Products Design Inc., USA), which were placed in-line on the flows escaping from each vessel. The tube that drives exhausted air to IRGA sensors and located outside the chamber is thermally insulated and reduced to a minimum length to prevent water from condense and undesired interference on the flow rate.
A water condenser was placed in the measuring line before the IRGA sensors. It is made of a copper serpentine containing a circulating liquid (mixture $1: 1 \mathrm{v} / \mathrm{v}$, water : ethylene glycol) refrigerated by a cryostat (Science/Electronics, USA) to a temperature below the dew point, inserted in polymethylmethacrylate, air-tight tubing; the condensed water is automatically discharged by gravity thanks to a solenoid valve that opens periodically.

A second in-line dryer consisting of a polymethylmethacrylate, air-tight tube (diameter $3 \mathrm{~cm}$ ) containing granular calcium chloride (SIGMA-Aldrich, USA) removes the residual moisture from the exhausted air before it enters the IRGA sensors. Drying the exhaust air is necessary to ensure a correct operation of the IRGA sensors. The system is provided with two sequential IRGA sensors for measuring the $\mathrm{CO}_{2}$ concentration in the outflow air (method 1, Figure 1): a Leybold-Heraeus Binos ${ }^{\circledR}$ (Germany), for measurements within the range $0-3000 \mathrm{ppm}$ and an accuracy of $1 \%$, and a Gascheck by Edinburgh Sensors (UK), for concentrations up to $100000 \mathrm{ppm}$ and an accuracy of 3\%. The IRGA sensors are automatically switched in order to achieve the highest accuracy of $\mathrm{CO}_{2}$ concentration measurements and were calibrated using three certified mixes (SOL group, Italy) of air containing $\mathrm{CO}_{2}$ at known concentration $(824,2970$, and $80600 \mathrm{ppm}$ ). After each $\mathrm{CO}_{2}$ concentration measurement, the line is flushed with $\mathrm{CO}_{2}$-free air. At the end of the pneumatic circuit, adjacent to the IRGA sensors, there is a gas mass flow meter (Dwyer, Germany), with a flow range of $0-80 \mathrm{~L} \mathrm{~h}^{-1}$, and an in-line thermocouple (Tersid, Italy). The mass flow meter was calibrated using a soap bubble glass flow meter $(500 \mathrm{~mL})$, following the procedure adopted by Levy [16], and the thermocouple calculates the $\mathrm{CO}_{2}$ concentration at Lab working conditions. To ensure the continuous and reliable measurement of all parameters, the system was checked for gas leaks at each connection point using a diluted soap solution.

Analog sensor signals are converted and recorded by means of a data logging system. Here, a computer monitors the results, a bus-powered multifunction DAQ (NI USB6009, National Instruments, USA) acquires analog signals, and a digital output module (NI USB-6501, National Instruments, USA) controls the solenoid valves via a multiple-relay module board.

2.2. Software. The automation and monitoring of all parameters is performed by means of a customized software developed within a LabVIEW environment. The parameters monitored are inlet air pressure, environmental chamber temperature, $\mathrm{CO}_{2}$ concentration, temperature, and airflow rate of the exhausted air.

An appropriate measuring/cleaning sequence is ensured to monitor the parameters of the exhausted air. Since the sequence lasts 20 minutes for each vessel, a complete measurement cycle for 12 vessels lasts 4 hours, thus providing 6 series of data per day for each vessel.

In the first $5 \mathrm{~min}$ of each sequence (time required for measured signals to reach steady state), the air valve opens and the detector is thus purged with $\mathrm{CO}_{2}$-free air. During the cleaning cycle, a drain valve located at the bottom of the water condenser opens for 30 seconds to discharge the condensed 
water accumulated in the previous set of analyses. Next, the valve associated with the selected vessel opens for 15 minutes, while the air valve closes. The exhaust air of the selected vessel enters the infrared sensors until a steady state pattern is reached. In the last minute of this steady state phase, the software acquires the analog signals, released every second from each sensor, and converts them into average values.

Data for each sample is recorded, plotted, and displayed in final tables, graphs, and spreadsheets. The software is structured with a front panel that monitors the trial and shows the results in real time; possible errors occurring during the trial-such as flow line blockage or unexpected temperature or pressure line drops in the chamber-are continuously checked by the software. If called for, a specific alarm signal appears on the screen for each vessel.

2.3. Experimental Conditions. In keeping with several methodologies reported in the literature [17], our trials were conducted in triplicate: 3 vessels contained the inoculum, 3 vessels contained compost plus a reference biodegradable material (namely cellulose, Sigma-Aldrich), and 3 vessels contained compost plus specimen. Since the apparatus could drive up to 12 vessels, each trial involved two samples.

We carried out two biodegradation trials on three biopolymers: two different poly $(\varepsilon$-caprolactone) (PCL) composites (sample A and sample B) and a commercially available, compatibilized polylactic acid, and polybutyrate (PLA/ PBAT) blend (sample C, ECOVIO IS 1335, BASF, Germany). A polyethylene (PE) film (sample D) was used as negative reference. Each vessel charge included $276 \mathrm{~g}$ of inoculum (wet weight), which filled about two-thirds of the internal volume, plus $23 \mathrm{~g}$ of the specimen or reference material (Table 1). Twenty-three g (dry weight) of agricultural perlite, previously humidified up to its maximum water retention $(76.5 \%)$, was added to each vessel to reduce the bulk density of the inoculum and provide better air circulation in it. The plastic specimen was milled $(<1 \mathrm{~mm})$ and thoroughly mixed with the inoculum at the start of trial, ensuring a 1:6, plastic: inoculum weight ratio, on a dry matter basis. Throughout the trial, we shook the samples manually once per week to achieve more homogeneity in the degradation process of the specimen. The moisture content of the inoculum was adjusted to about $50 \%(\mathrm{w} / \mathrm{w})$ at the start of the trials and held constant by means of inlet air humidification. However, during the weekly shaking procedure, moisture was controlled by weighing each vessel and distilled water was added if necessary. The carbon and nitrogen content of the samples was determined using a CHNS analyser (Macro Cube, Elemental, Germany) equipped with selective traps for $\mathrm{CO}_{2}, \mathrm{H}_{2} \mathrm{O}$, and $\mathrm{SO}_{2}$ and detected by thermal conductivity. The ash content was determined as weight loss at $650^{\circ} \mathrm{C}$ for $24 \mathrm{~h}$ in a muffle furnace on samples previously oven dried at $105^{\circ} \mathrm{C}$. The inoculum employed in the biodegradation trials was the compost obtained at the end of a static composting procedure set up for OMW management, as described in Altieri and Esposito [18] and Altieri et al. [19]. The OMW compost used as inoculum was produced in 2013 and stored dry until the day before use, when it was moistened to about $50 \%$ for the trial. This procedure keeps alive the microorganism populations that drive the biodegradation of the plastic samples. The environmental chamber was set at $58 \pm 2^{\circ} \mathrm{C}$, which is representative of full-scale composting. Vessel flows were set at $20 \mathrm{~L} \mathrm{~h}^{-1}$ and fresh air at $60 \mathrm{~L} \mathrm{~h}^{-1}$ to adequately clean up the measurement line.

The degree of biodegradation is determined from the amount of specimen carbon converted to $\mathrm{CO}_{2}$ by the end of the trial. $\mathrm{CO}_{2}$ emissions, automatically calculated for each measurement cycle and then cumulated, are converted to mass values with the following general equation:

$$
\mathrm{CO}_{2 \text { sample }}=\frac{\mathrm{Q} \cdot \mathrm{CO}_{2} \cdot \Delta t \cdot M\left(\mathrm{CO}_{2}\right)}{V_{m}},
$$

where $Q$ is the flow rate measured with the gas mass meter, $\mathrm{CO}_{2}$ is the $\mathrm{CO}_{2}$ concentration measured with the IRGA sensors and corrected for the background $\mathrm{CO}_{2}$ concentration of the inlet $\mathrm{CO}_{2}$-free air, $\Delta t$ is the period of the measurement cycle, $M\left(\mathrm{CO}_{2}\right)$ is the molar mass of $\mathrm{CO}_{2}$, and $V_{m}$ is the volume occupied by one mole of $\mathrm{CO}_{2}$ at the exhaust-air temperature, as determined by the local in-line sensor. The molar volume of $\mathrm{CO}_{2}$ is calculated using the following:

$$
V_{m}=R \cdot \frac{T_{\text {out }}}{P_{\mathrm{atm}}}
$$

where $R$ is the ideal gas constant, $T_{\text {out }}$ is the temperature of the outlet flow, and $P_{\text {atm }}$ is the atmospheric air pressure.

The percentage of biodegradation for each specimen is calculated as

$$
\% D_{\text {sample }}=\frac{\mathrm{CO}_{2 \text { sample }}-\mathrm{CO}_{2 \text { inoculum }}}{\mathrm{ThCO}_{2}},
$$

where $\mathrm{CO}_{2 \text { sample }}$ and $\mathrm{CO}_{2 \text { inoculum }}$ are both calculated with (1) and $\mathrm{ThCO}_{2}$ is the theoretical (maximum) amount of $\mathrm{CO}_{2}$ released from the fully mineralized sample, calculated on the basis of its organic carbon content.

2.4. Check of the $\mathrm{CO}_{2}$ Emissions by the Titration Method. In order to confirm the results obtained by the experimental apparatus, the amount of $\mathrm{CO}_{2}$ released during biodegradation was also checked using the standard titration method reported in ISO 17556:2012 [20]. The comparison of the methods was based on a fixed observation time. Exhausted air from a randomly chosen vessel was directed towards a series of three 2-L vessels fitted with gas diffusers and containing saturated $\mathrm{Ba}(\mathrm{OH})_{2}$, solution able to capture the $\mathrm{CO}_{2}$ (method 2 , Figure 1). In fact, when $\mathrm{CO}_{2}$ enters the scrubbing vessels, it reacts as follows:

$$
\mathrm{Ba}(\mathrm{OH})_{2}+\mathrm{CO}_{2} \longrightarrow \mathrm{BaCO}_{3}+\mathrm{H}_{2} \mathrm{O}
$$

The barium carbonate formed is insoluble and precipitates. The excess of $\mathrm{Ba}(\mathrm{OH})_{2}$ in the three $\mathrm{CO}_{2}$ scrubbing vessels was then determined by end-point titration with $\mathrm{HCl}$, using phenolphthalein as indicator, according to the following equation:

$$
\mathrm{Ba}(\mathrm{OH})_{2}+2 \mathrm{HCl} \longrightarrow \mathrm{BaCl}_{2}+2 \mathrm{H}_{2} \mathrm{O}
$$


TABLE 1: Characteristics of the samples used in the trials of the experimental apparatus.

\begin{tabular}{|c|c|c|c|c|c|c|c|}
\hline & & Inoculum & A & B & C & $\mathrm{D}$ & \multirow{2}{*}{ Ref. } \\
\hline & & Compost & PCL & PCL & PLA/PBAT & PE & \\
\hline Amount & g vessel $^{-1}$ & 276.0 & 23.0 & 23.0 & 23.0 & 23.0 & 23.0 \\
\hline Moisture & $\%$ & 51.10 & 1.14 & 2.75 & 0.41 & 0.46 & 0 \\
\hline Ash $^{*}$ & $\%$ & 18.00 & 1.21 & 2.07 & 5.90 & 0.35 & 0 \\
\hline Carbon* & $\%$ & 44.7 & 60.5 & 59.0 & 58.4 & 84.0 & 44.4 \\
\hline Nitrogen ${ }^{*}$ & $\%$ & 4.50 & 2.56 & 3.76 & 0.18 & 1.09 & 0 \\
\hline $\mathrm{ThCO}_{2}$ & g vessel $^{-1}$ & 221.2 & 50.4 & 48.4 & 49.0 & 70.5 & 37.4 \\
\hline
\end{tabular}

* Data are referred on dry matter base; PCL, poly(e-caprolactone) composite; PLA/PBAT, compatibilized polylactic acid and polybutyrate blend; PE, polyethylene (negative reference); Ref., reference (pure cellulose, Sigma-Aldrich); $\mathrm{ThCO}_{2}$, theoretical $\mathrm{CO}_{2}$ emission.

From (4) and (5), one can calculate the number of mmoles of $\mathrm{CO}_{2}$ produced in a fixed time as follows:

$$
\text { mmoles } \mathrm{CO}_{2}=\text { mmolesBa }(\mathrm{OH})_{2}-\frac{\text { mmolesHCl}}{2},
$$

where mmoles $\mathrm{Ba}(\mathrm{OH})_{2}$ is the initial number of mmoles of $\mathrm{Ba}(\mathrm{OH})_{2}$. The $\mathrm{CO}_{2}$ scrubbing solution was prepared by dissolving $\mathrm{Ba}(\mathrm{OH})_{2}$ in distilled water, filtering it, and sealing it to prevent absorption of $\mathrm{CO}_{2}$ from the atmosphere. It was then stored as standard clear solution. However, since it is quite unstable, the actual concentration of the initial solution was determined by titration with a standard $\mathrm{HCl} 0.05 \mathrm{M}$ prior to each use.

\section{Results and Discussion}

The findings of the biodegradation experiment carried out on A and B plastic polymers (Table 1) are given in Figures 4 and 5. Both graphics show average values with related standard error, evaluated every four hours and calculated using (1) $\left(\mathrm{CO}_{2}\right.$ emission per vessel) and by (3) (degree of biodegradation). Figure 4 shows a very high degradation rate for both plastic polymers tested-even higher than that of the biodegradable standard (cellulose) - starting right from the early stages of the trial. In fact, after about 20 days, both plastics reached a percentage of biodegradation higher than $80 \%$ (Figure 5), about double that of cellulose (about 45\%). The high nitrogen levels of specimens A and B (Table 1) might explain their more rapid biodegradation; indeed, biomass having a lower $\mathrm{C} / \mathrm{N}$ ratio is more easily degraded by microorganisms, which can then find an appropriate source of nitrogen for supporting their metabolism and reproduction.

In the first trial, after 10 days, the inoculum showed a cumulated emission of $9.4 \pm 0.1 \mathrm{gCO}_{2}$ vessel $^{-1}$, which corresponds to $86.3 \pm 1.3 \mathrm{mgCO}_{2}$ per gram of volatile solids-a value falling in the range prescribed by ISO 14855-1:2012 and considered optimal for successfully conducting biodegradation tests under composting conditions [17]. Thus, compost based on OMW as inoculum showed to be adequately rich in microorganisms that drive biodegradation of the specimens tested. At the end of the first trial, a cumulated emission equal to $31.0 \pm 3.3 \mathrm{gCO}_{2}$ vessel $^{-1}$ was registered for the reference material (cellulose), which corresponds to $45.0 \pm 9.2 \%$ biodegradation (coefficient of variation, $\mathrm{CV}=20.5 \%$ ). At that

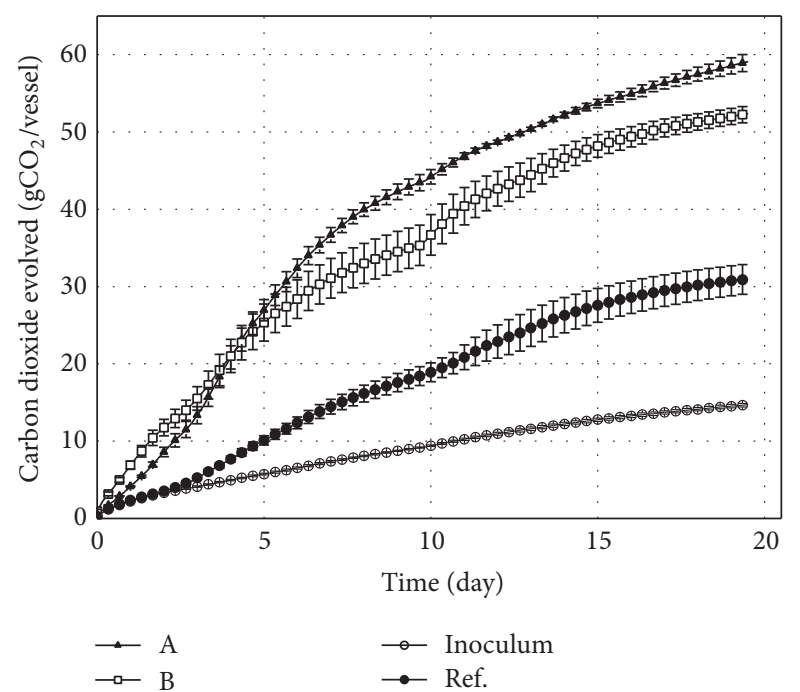

FIGURE 4: First biodegradation trial: cumulated $\mathrm{CO}_{2}$ emissions per vessel. (A, B) PCL composites; (Ref) reference, cellulose. Error bars refer to standard error $(n=3)$.

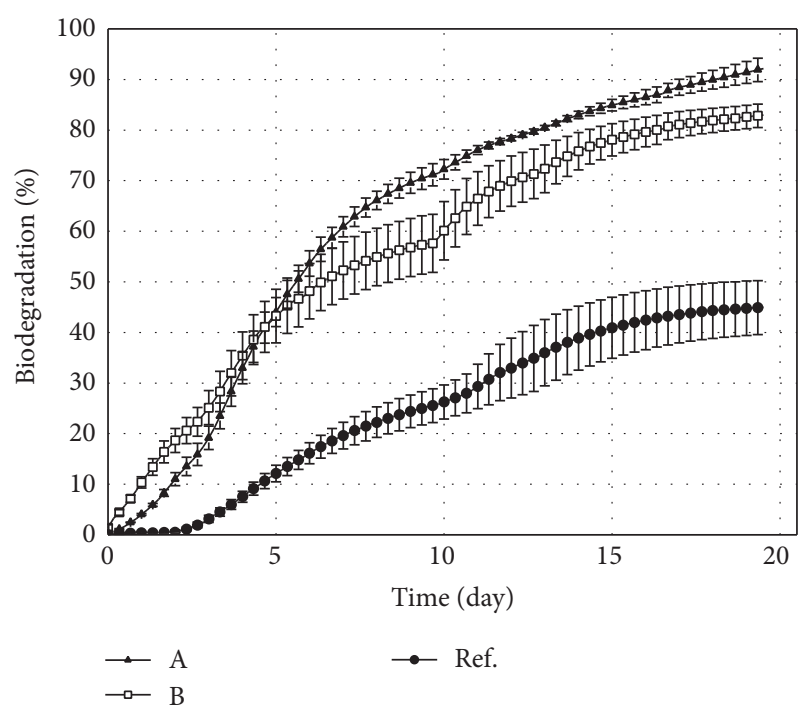

FIGURE 5: First biodegradation trial: percentage of mineralization of polymers tested. (A, B) PCL composites; (Ref) reference, cellulose. Error bars refer to standard error $(n=3)$. 


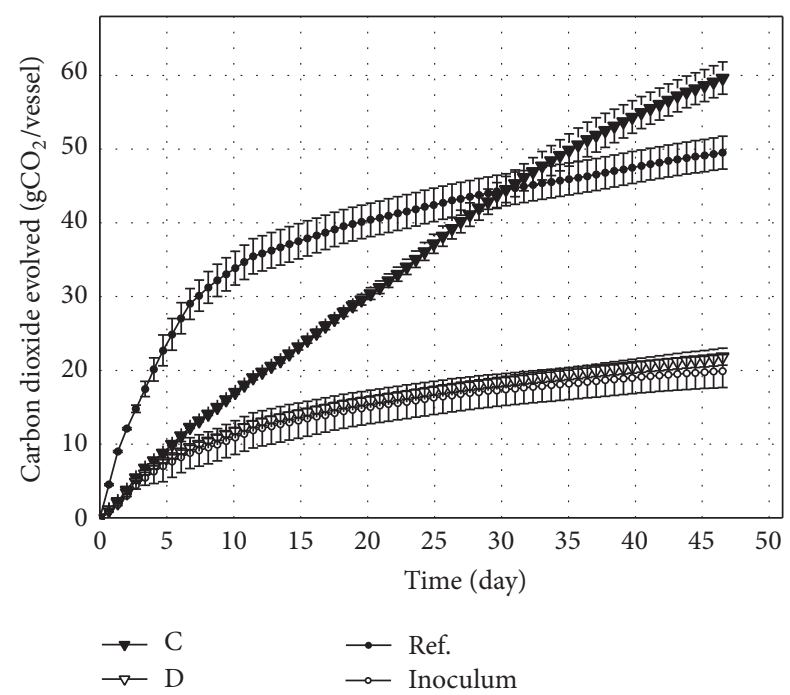

FIGURE 6: Second biodegradation trial: cumulated $\mathrm{CO}_{2}$ emissions per vessel. (C) PLA/PBAT blend; (D) polyethylene film, negative reference; (Ref) reference, cellulose. Error bars refer to standard error $(n=3)$.

time point, the amount of cumulated $\mathrm{CO}_{2}$ emission for the inoculum triplicates was $14.7 \pm 0.4 \mathrm{gCO}_{2}$ vessel $^{-1}$, which is the value subtracted from the cumulated $\mathrm{CO}_{2}$ emissions registered both for the reference and specimen vessels, as specified in (3). At the end of the first trial, a cumulated $\mathrm{CO}_{2}$ emission equal to $59.1 \pm 2.0 \mathrm{gCO}_{2}$ vessel $^{-1}$ and $52.3 \pm$ $1.8 \mathrm{gCO}_{2}$ vessel $^{-1}$ was found for specimens $\mathrm{A}$ and $\mathrm{B}$, respectively. This corresponds to $92.1 \pm 4.1 \%$ and $82.9 \pm 4.0 \%$ biodegradation. Moreover, the low variability among the replicates corroborates the validity of the first trial.

The results of the second biodegradation trial performed on specimens $\mathrm{C}$ (a commercial plastic polymer) and D (polyethylene as negative reference) are shown in Figures 6 and 7. Here, the rate of biodegradation for specimen $\mathrm{C}$ was much lower than that of the reference, at least in the first ten days of the trial (Figure 6). It was also much lower than the rates registered in the first trial for specimens A and B (Figure 4). As expected, the rate for the negative reference was almost zero (Figure 6). Due to the lower biodegradation rate, trial two was necessarily longer; it lasted 46.5 days, the time point at which both specimen $C$ and cellulose reached about $80 \%$ biodegradation (Figure 7). In the second trial, a cumulated $\mathrm{CO}_{2}$ emission of $10.7 \pm 2.4 \mathrm{gCO}_{2}$ vessel $^{-1}$, corresponding to $96.4 \pm 21.6 \mathrm{mgCO}_{2}$ per gram of volatile solid, was registered after ten days. This value is comparable to that of the first trial, thus confirming the repeatability of the test and the suitability of the OMW compost as inoculum. At the end of the second trial, a cumulated $\mathrm{CO}_{2}$ emission of $49.5 \pm 3.9 \mathrm{gCO}_{2}$ vessel $^{-1}$ was registered in the reference vessels, corresponding to $79.0 \pm 10.3 \%$ biodegradation and a $13 \%$ coefficient of variability. At the end of the second biodegradation trial, a cumulated $\mathrm{CO}_{2}$ emission for the inoculum triplicates equal to $19.9 \pm 3.9 \mathrm{gCO}_{2}$ vessel $^{-1}$ was also detected, a value then subtracted from the total cumulated $\mathrm{CO}_{2}$ emissions recorded for the reference and specimen vessels, as specified in (3).

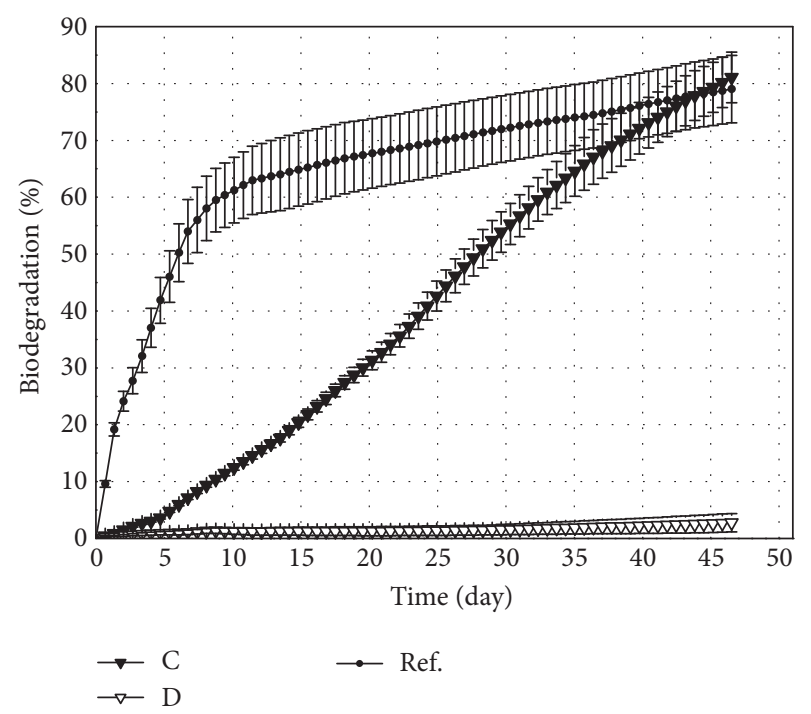

FIGURE 7: Second biodegradation trial: percentage of mineralization of polymers tested. (C) PLA/PBAT blend; (D) polyethylene film, negative reference; (Ref) reference, cellulose. Error bars refer to standard error $(n=3)$.

Furthermore, cumulated emissions of $59.6 \pm 3.8 \mathrm{gCO}_{2}$ vessel $^{-1}$ and $21.9 \pm 2.0 \mathrm{gCO}_{2}$ vessel $^{-1}$ were found for specimens $\mathrm{C}$ and $\mathrm{D}$ (negative reference), respectively, which correspond to $81.1 \pm 7.7 \%$ and $2.8 \pm 2.8 \%$ biodegradation. These results confirm the validity of the second test, since specimen $\mathrm{C}$ exhibited an acceptable variability (9.5 CV\%) and specimen $\mathrm{D}$, as expected, underwent no significant biodegradation. Although the respiration activity of the inoculum should be carefully considered when comparing results, the cumulated $\mathrm{CO}_{2}$ emission registered for the inoculum and the reference material in both biodegradation trials agreed with those reported in the literature [10].

Check-tests using the titration method to measure $\mathrm{CO}_{2}$ emissions were performed on the outflows from cellulose vessel and polymer A vessel and lasted 139 and 225 minutes, respectively. In 139 minutes, cellulose vessel emitted $213.5 \mathrm{mgCO}_{2}$ according to the titration method and $210.8 \mathrm{mgCO}_{2}$ according to the IRGA. Thus, the agreement was very good (1.24\%). In 225 minutes, polymer A vessel emitted $287.8 \mathrm{mgCO}_{2}$ according to the titration method and $266.7 \mathrm{mgCO}_{2}$ according to the IRGA, a difference of $7.33 \%$. It is worth noting that the check-tests were performed on days 11 and 12 of the trial, during a very active biodegradation phase. Titration tests confirmed the reliability of the apparatus designed and built for assessing the ultimate biodegradation of plastic polymers under composting condition.

\section{Conclusions}

In this study, we developed an experimental apparatus for analysing the biodegradability of plastic polymers under controlled composting conditions. Using direct infrared gas analysis, we evaluated the cumulative carbon dioxide emissions of two poly( $\varepsilon$-caprolactone) (PCL) composites and a compatibilized polylactic acid and polybutyrate (PLA/PBAT) 
blend, which are made of renewable materials and can be used for specific applications in the agricultural sector. Their biodegradation conducted in olive-mill waste compost used as inoculum was proved in a very short time. Our findings were checked $(\mathrm{CV}<10 \%)$ by means of a cumulative measurement technique, performed simultaneously during a fixed time, and based on acid-base titration, using saturated $\mathrm{Ba}(\mathrm{OH})_{2}$ to trap the evolved carbon dioxide.

The apparatus proves to be quite flexible; in fact, different environments can be simulated by means of small changes, such as the design of the vessels, the inoculum used (e.g., soil or water, instead of compost), or the environmental parameters under control (e.g., oxygen). This makes it possible to evaluate a wide range of different biodegradation scenarios. Moreover, it reduces the likelihood of systematic errors that might result from use of the laborious technique necessary for the standard acidimetric titrations.

This study may serve as basis for further investigations on biopolymer degradation in different composting conditions and environment. Furthermore, laboratory data may be used for upscaling results, in order to mitigate plastic waste issues of the agricultural sector towards an efficient use of renewable resources.

\section{Competing Interests}

The authors declare that they have no competing interests.

\section{Acknowledgments}

This research was carried out within the framework of IGAN ECO-POT project, funded by Regione Toscana, Italy (PSR 2007-2013), and was partially supported by the DFG RTG 1703 "Resource Efficiency in Interorganizational Networks."

\section{References}

[1] R. A. Gross and B. Kalra, "Biodegradable polymers for the environment," Science, vol. 297, no. 5582, pp. 803-807, 2002.

[2] EC, EU Focus on Waste Management, Directorate-General Environment, Nuclear Safety and Civil Protection, Office for Official Publications of the European Communities, EC, Luxembourg City, Luxembourg, 1999.

[3] J.-C. Huang, A. S. Shetty, and M.-S. Wang, "Biodegradable plastics: a review," Advances in Polymer Technology, vol. 10, no. 1, pp. 23-30, 1990.

[4] M. Alexander, "Biodegradation of chemicals of environmental concern," Science, vol. 211, no. 4478, pp. 132-138, 1981.

[5] A. Wojtowicz, Biodegradability and Compostability of Biopolymers, John Wiley \& Sons, New York, NY, USA, 2009.

[6] International Organization for Standardization (ISO), "Specification for compostable plastics," ISO 17088:2012, International Organization for Standardization (ISO), Geneva, Switzerland, 2012.

[7] European Committee for Standardization (CEN), "Packagingrequirements for packaging recoverable through composting and biodegradation - test scheme and evaluation criteria for the final acceptance of packaging," CEN EN 13432:2000, 2000.
[8] R. Barrena, T. Gea, S. Ponsá et al., "Categorizing raw organic material biodegradability via respiration activity measurement: a review," Compost Science \& Utilization, vol. 19, no. 2, pp. 105113, 2011.

[9] R. Jayasekara, G. T. Lonergan, I. Harding, I. Bowater, P. Halley, and G. B. Christie, "An automated multi-unit composting facility for biodegradability evaluations," Journal of Chemical Technology and Biotechnology, vol. 76, no. 4, pp. 411-417, 2001.

[10] T. Kijchavengkul, R. Auras, M. Rubino, M. Ngouajio, and R. Thomas Fernandez, "Development of an automatic laboratoryscale respirometric system to measure polymer biodegradability," Polymer Testing, vol. 25, no. 8, pp. 1006-1016, 2006.

[11] R. Pantani and A. Sorrentino, "Influence of crystallinity on the biodegradation rate of injection-moulded poly(lactic acid) samples in controlled composting conditions," Polymer Degradation and Stability, vol. 98, no. 5, pp. 1089-1096, 2013.

[12] P. Dřímal, J. Hoffmann, and M. Družbík, "Evaluating the aerobic biodegradability of plastics in soil environments through GC and IR analysis of gaseous phase," Polymer Testing, vol. 26, no. 6, pp. 729-741, 2007.

[13] A. Ohtaki and K. Nakasaki, "Report: ultimate degradability of various kinds of biodegradable plastics under controlled composting conditions," Waste Management and Research, vol. 18, no. 2, pp. 184-189, 2000.

[14] F. Castellani, A. Esposito, V. Stanzione, and R. Altieri, "Analysis of emissions from lab-scale composting equipment: data for a sustainability challenge," in Proceedings of the 14th International Conference on Environmental Science and Technology, T. D. Lekkas, Ed., Rhodes, Greece, September 2015.

[15] International Organization for Standardization (ISO), "Determination of the ultimate aerobic biodegradability of plastic materials under controlled composting conditions-method by analysis of evolved carbon dioxide-part 1: general method," ISO 14855-1:2012, International Organization for Standardization (ISO), Geneva, Switzerland, 2012.

[16] A. Levy, "The accuracy of the bubble meter method for gas flow measurements," Journal of Scientific Instruments, vol. 41, no. 7, pp. 449-453, 1964.

[17] U. Pagga, "Testing biodegradability with standardized methods," Chemosphere, vol. 35, no. 12, pp. 2953-2972, 1997.

[18] R. Altieri and A. Esposito, "Olive orchard amended with two experimental olive mill wastes mixtures: effects on soil organic carbon, plant growth and yield," Bioresource Technology, vol. 99, no. 17, pp. 8390-8393, 2008.

[19] R. Altieri, A. Esposito, and T. Nair, "Novel static composting method for bioremediation of olive mill waste," International Biodeterioration \& Biodegradation, vol. 65, no. 6, pp. 786-789, 2011.

[20] International Organization for Standardization (ISO), "Plastics-determination of the ultimate aerobic biodegradability of plastic materials in soil by measuring the oxygen demand in a respirometer or the amount of carbon dioxide evolved," ISO 17556:2012, International Organization for Standardization (ISO), Geneva, Switzerland, 2012. 

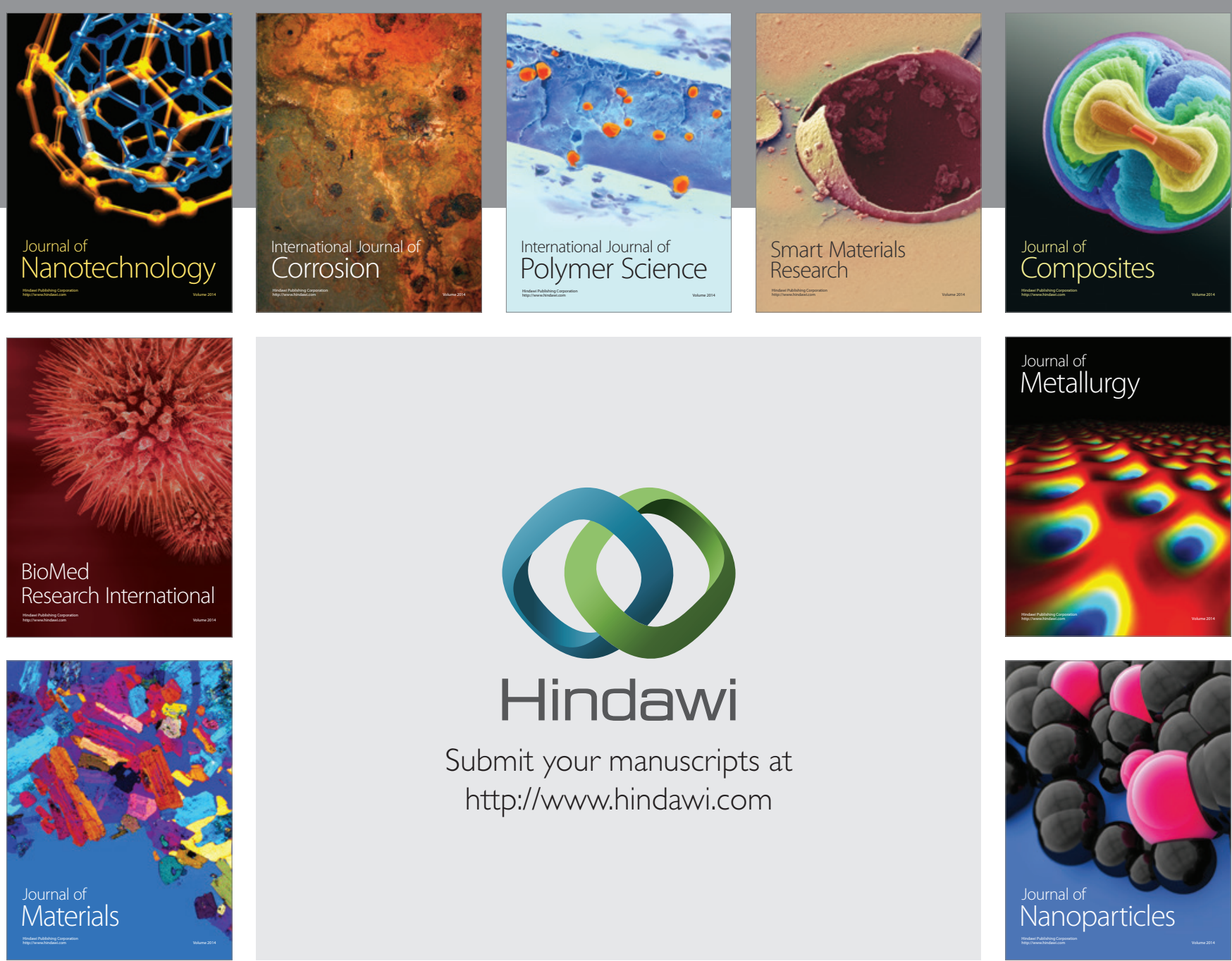

\section{Hindawi}

Submit your manuscripts at

http://www.hindawi.com

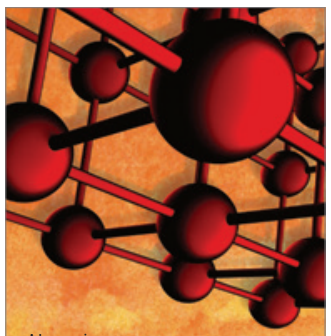

Materials Science and Engineering
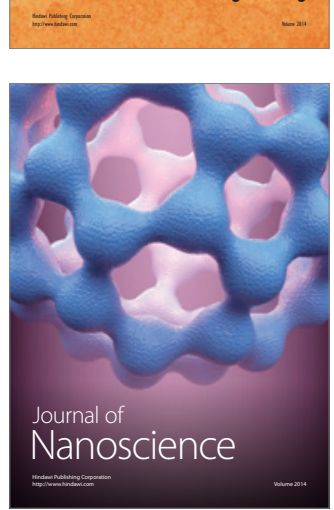
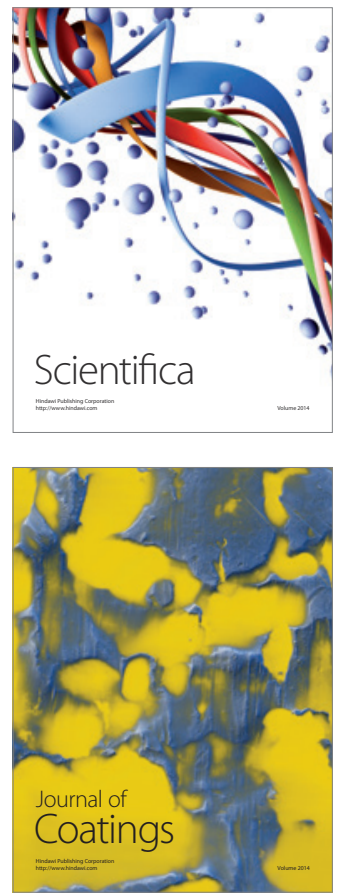
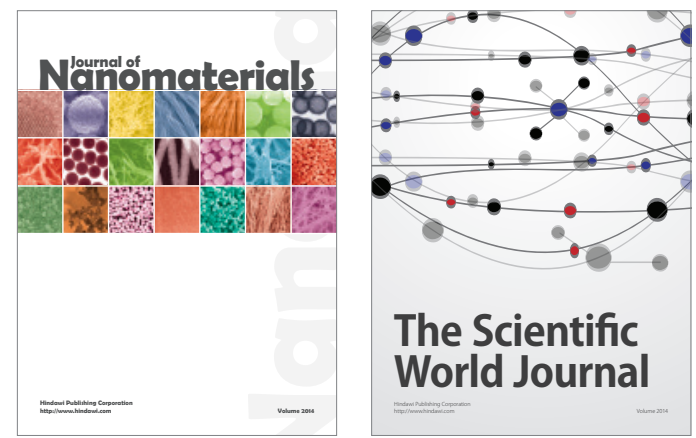

The Scientific World Journal
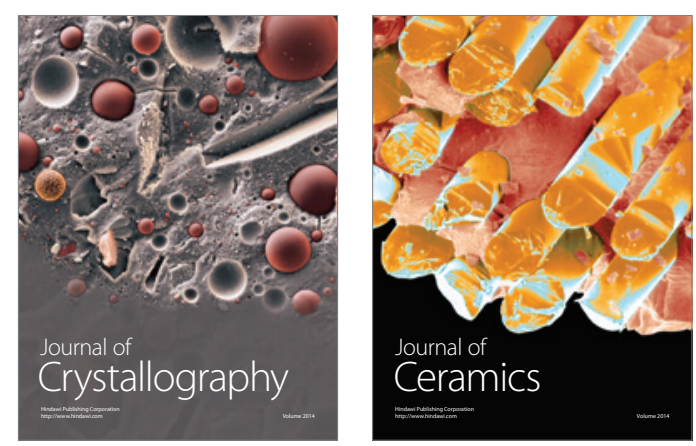
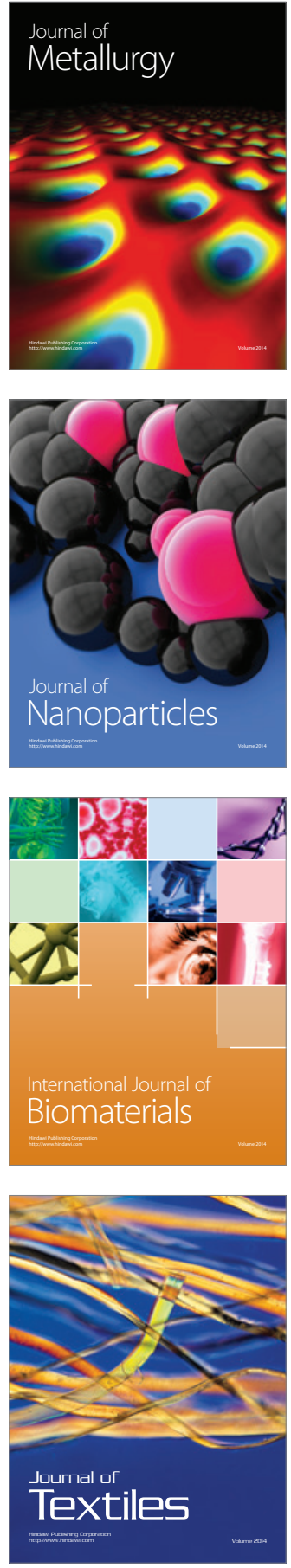